International Journal of Educational Studies

ISSN: 2641-533X

Vol. 3, No. 2, pp. 48-52.

2020

DOI: $10.53935 / 2641-533 x . v 3 i 2.140$

(C) 2020 by the authors; licensee Academic Publishing Group

\section{Scholar Failure: From the University Students' Perception}

¿Damián-Notario Jade Isabel: Teacher of Pedagogy and Teaching Practice (UPN042), Mexico.

Torres-Zapata Ángel Esteban: Manager of the Degree in Nutrition, Faculty of Health Sciences, Autonomous University of Carmen, Mexico.

Rivera-Dominguez, Javier: Gestor of the Degree in Psychology, Faculty of Health Sciences, Autonomous University of Carmen, Mexico.

Villanueva Echavarría José Rafael: Full-time Professor of the Bachelor of Nursing, Faculty of Health Sciences, Autonomous University of Carmen, Mexico.

Moguel-Ceballos Juan Eduardo: Full-time Professor of the Bachelor of Nutrition, Faculty of Health Sciences, Autonomous University of Carmen, Mexico.

\begin{abstract}
Scholar failure, defined as the insufficient quantitative performance of the students' potential which impedes them to achieve the minimum parameters stablished by an educative institution, generating in the student a feeling of letdown, and low performance, becoming a prelude to educational lagging and school dropout. The goal of this research was to determine the reasons of academic failure from the student perspective. This is a descriptive, crosssectional study, with a non-probabilistic by convenience sampling, 66 students participated on it, who failed on at least one course on the August - December 2019 scholar period. The instrument applied gathers information such as: Name, gender, age, enrollment code, cycle, and the following question: Which do you consider where the reasons for your academic failure? The answers where later classified as follows 1) inherent to the student 2) inherent to the teacher, 3) inherent to the family or the family's economy 4) inherent to the curricula, and 5) inherent to the institution. Results show that the two main reasons of academic failure from a student's perspective are inherent to the student (49.5\%) and inherent to the teacher (26.6\%). These results, allow to determine analysis and opportunity zones that must be addressed to reduce the scholar failure and school dropout rates.
\end{abstract}

Key words: Scholar failure, Scholar failure causes, Higher education, Mexico.

\section{Introduction}

Higher Education system in Mexico faces many issues, among these, the high rates of academic failure, which have to be addressed as soon as possible, since they have a direct impact in the public welfare. (Velázquez Narváez \& González Medina, 2017).

Scholar failure, defined as the insufficient quantitative performance of the students' potential which impedes themto achieve the minimum parameters stablished by an educative institution, (Yépez-Herrera, Rivera-Heredia, Valadez-Sierra, Pérez-Daniel, \& González-Betanzos, 2019) generates in the students a

International Journal of Educational
Studies
Vol. 3, No.2, pp. $48-52$
2020
DOI: $10.53935 / 2641-533 x . v 3 i 2.140$
Corresponding Author: Damián-Notario Jade
Isabel
Funding: This study received no specific
financial support.
Article History:
Received: 2 March 2020
Revised: 15 May 2020
Accepted: 7 July 2020
Published: 5 August 2020
C) 2020 by the authors; licensee Academic
Publishing Group
Publishing Group 
feeling of letdown since their low performance would not allow them to continue to the next scholar levels, becoming the antechamber for academic lag and school dropout (Fernández et al., 2017).

As such, course reprobation is a part of a more general phenomenon called "Scholar failure", which is defined as, the struggle that some students manifest to acquire information, skills and attitudes that are taught in school, generating low academic performance, course reprobation, and in its extreme form school dropout (Martínez, Lima, Padilha, \& Montes, 1998). Due to this, the student is classified in different categories such as: repeating student, irregular student, regular student, and lagging student.

There are many ways to categorize the causes of scholar failure, among these we can find: 1) Social and familiar origin reasons. Familiar dysfunction or disarticulation, inability to adapt to a different social environment, working students, married students or early parenthood students. 2)Psychological origin reasons: absence of life goals or wrong career choice; 3) Academic Performance related reasons: inadequate academic profile, lack of study habits; 4) Physical reasons: health issues, and poor diet (Salazar \& Espinoza, 2017) and 5) Reasons related to the Academic Institution: These are related to teacher's performance, curricular contents, the nature of student - professor relationship, the overall congruency of evaluation methods, academic and administrative requirements for course accreditation and the quality of the support organization offered by the academic institution for the learning process (Martínez et al., 1998).

\subsection{Research Context}

Evaluation and accreditation of higher education in Mexico is nowadays carried by specializedorganisms and institutions, that have built a wide reference frame system, which compresses criteria, indexes, standards, evaluation tools and promotion strategies to procure quality, and continuous improvement to drive the social longing for academic parity. Those who evaluate higher education programs, have to recognize on a first instance the higher education organizations (IES) that teach them and whom periodically apply their own auto-evaluations; on the other side there are external evaluations carried out by academic peers who integrate the Inter-Institutional Committees for Higher Education Evaluation (CIEES) and accreditation organisms recognized by the Higher Education Accreditation Council (COPAES); additionally the country has an specialized institution that evaluates health related educational programs: The Health's Human Resources Formation Inter-Institutional Commission (CIFRHS), to validate their relevance and quality, all of these organism have found during their evaluations academic failure, school dropout and reduced terminal efficiency as a constant (Torres, Acuña, Guadarrama, Solís, \& Flores, 2017).

Parting from these evaluations, on a broad level in Mexico can be found:

- $\quad$ High Academic Failure Rates

- High School Dropout Rates

- Low Academic Performance

- $\quad$ Academic Lag

(De la Garza Aguilar, 2013; Quintela, 2013; Rodriguez, Espinoza, Ramirez, \& Ganga, 2018; Torres-Zapata, Rivera Domínguez, Flores López, García Reyes, \& Castillo Trejo, 2020).

The identification of related causes to academic failure, allows to propose and carry out actions, that enable students who enroll to a higher education institution to maintain their academic status and later on to graduate. Due to this fact the main goal of this research was to determine the reasons for academic failure from a university student perspective.

\subsection{Development Methods}

The following research accounts for the third phase of the "Stress Events in University Students: An Obligatory Analysis to Reinforce the Tutorial System", in which the causes for academic failure are analyzed.

This is a descriptive, non-experimental, cross-sectional study. Research population consisted of 179 students from both genders, enrolled on the August - December 2019. A non-probabilistic convenience sampling was used; data recollection was carried out on December, at the end of the scholar cycle.

Selection criteria: 66 students who had at least reproved one academic course on the scholar period August - December 2019 or had prior evidence of academic failure (which was verified through the academic records) were included. The students were required to convey their willingness to participate in the study.

The information used on this research, were extracted from a questionary available at the Institutional web page. The data gathered includes name, gender, age, enrollment number, scholar cycle and the students' 
answer to the question: Which do you consider were the reasons for your academic failure? The answers were later classified as follows: 1) inherent to the student, 2) inherent to the teacher, 3) inherent to the family or the family's economy 4) inherent to the curricula, and 5) inherent to the institution.

Descriptive statistics were applied to gathered data, using Microsoft Excell@ spreadsheets.

The research was conducted following the General's Health Code, in regards of health research considerations (Salazar \& Espinoza, 2017) specifically on the social rights guarantee and health safety on research activities paragraphs, under informed consent of the participants.

Before the beginning of the study written authorization was sought with the career coordinator, informing about the main and specific research goals; later on it was evaluated by the bioethics council, to discard any conflict of interests, a positive assessment was achieved. The research was coordinated by the "Education and Administration" discipline group.

\section{Results and Discussion}

As a first step, the scope of the scholar failure problem was determined for the August - December 2019 scholar cycle. To accomplish this the percentage of students who had at least one reproved course during this particular period (August - December 2019) was obtained, resulting in 36.87\% (66 out of 179 students) within an average age of $21.67 \pm 3.71$ years old, a minimum age of 17years on the lower end and a maximum of 43 years on the higher end, with a predominance of females $(81.82 \%)$.

The courses that had a higher rate of reprobation, account for $23.08 \%$ (12 out of 52) of the total courses, among these $5.77 \%$ (3) are focused on developing mathematic, foreign languages (English), and analytical skills; 7.69\% (4) are part of the Basic Biomedical Science Courses and, 9.62\% (5) belong to the specific career skills (clinical area).

Regarding the number of course units that students tend to reprove, $18.18 \%$ of them fail only one unit, $65.15 \%$ fails two and 16.67 three or more.

Later on the reasons disclaimed by the students as causes for academic failure were categorized. It is important to report, that the students had the possibility to mention more than one reason for academic failure, and that these could also be pooled, for example, working issues and getting married, also conflicts with the professor and lack of motivation, etc., due to this situation, in order to account for the totality of the data, each answer was treated individually, getting a total of 188 answers. Summary Table 1 shows the distribution of reason for failure from the students' perspective.

Table 1. Main Academic Failure Reasons from the Students' Perspective

\begin{tabular}{lll}
\hline Reasons for failure & f & \% \\
\hline Inherent to the student & 95 & 49.5 \\
Inherent to the teacher & 47 & 26.6 \\
Inherent to the family or the family's economy & 20 & 10.4 \\
Inherent to curricula & 17 & 8.9 \\
Inherent to the academic institution & 9 & 4.6 \\
Total & 188 & 100 \\
\hline
\end{tabular}

\subsection{Summary}

The students acknowledge that the main reason for scholar failure, falls among the category of "Inherent to the student", stating the following: 1) studying only the day before tests or feeling under pressure,2) lack of organization resulting in poor results and omissions on school assignments, 3) not keeping class notes, 4) skipping classes, 5) lack of self-motivation, 6) health related issues, 7) lack of involvement and participation on classes (fear of embarrassment), 8) lack of basic knowledge needed as a pre-requisite for the course and, 9) inadequate use of social networks. Findings reported for this research are similar on magnitude to those reported by Martínez, Sánchez, Hernández, Sánchez, and Salazar (2017) 54.8\%, Vargas, Brito, Leal, De la Cruz, and Fernández (2015) 56\% and Llanes Castillo, Cervantes López, Pena Maldonado, and Saldivar González (2013) but on a lesser degree when compared to Amado, Velázquez, Páez, Luján, and Bernal (2014) who reported an $80 \%$.

The inherent to the teacher category, is the second most mentioned reason that students believe are the cause for their academic failure, results are lower than those reported by Saucedo, Perera, Maldonado, and 
Padilla (2014) who reported a 49\%. Aspects accounted for this category are: 1) Lack of teacher's feedback on course contents and school assignments, 2) Bad student - teacher relationship, 3) Poor professors' familiarity with the course contents. 4) Poor teaching methods and technics, 5) Evaluation criteria not being observed (as stated on syllabus) 6) professor's nonattendances and,

7) Scarce simulation practices.

The premises regarding the reasons for academic failure for the "Inherent to the family and the family's economy" are: 1) Unemployed parents needs to work to help the family's economy, 2) Don't have the necessary means to study, 3) Bad relationship with family members, 4) Foreign student who has to pay rent, 5) Dysfunctional family and, married or early parenthood students. The results obtained for this category are similar to those reported by who mentions that $14.8 \%$ claimed to have failed because they study and work at the same time; but are lower to those reported by Amado et al. (2014) who indicates that $46 \%$ of the participants claimed to have reproved due to social and familiar issues, including pregnancy and parenthood.

The potential failure reasons that comprise the inherent to curricula category, are: 1) courses with a high degree of difficulty, 2) conflicting schedules, 3) elevated number of courses on a certain scholar period, 4) high amounts of information, 5) limited time to cover course syllabus and, 6) Excess of school assignments.

Finally, the reasons for scholar failure "inherent to the academic institution" had a low prevalence, here were considered the following: 1) uncomfortable chairs, 2) slow academic registration system network, 3) lack of teacher's and, 4) Poor course offerings.

Finalmente, las causas de reprobación "Inherentes a la institución" presentan una incidencia baja, se constituyen por elementos como: 1) Sillas incomodas, 2) Sistema institucional para cargar cursos lento, 3) Insuficientes profesores y, 4) Oferta de cursos.

\section{Conclusions}

Academic failure in Mexico is a phenomenon on the rise, this creates a continuous search for solutions which involves everyone involved on the higher education system.

This research strengthens the findings of other researchers, it also provides novel information to contribute to the academic success of higher education students, through the definition and delimitation of the main reasons perceived by students as the causes of their academic failure.

Data analysis shows that there are two main reasons that promote academic failure and moreover, school dropout; the first one being inherent to the student(49.5\%): 1) studying only the day before tests or feeling under pressure,2) lack of organization resulting in poor results and omissions on school assignments, 3) not keeping class notes, 4) skipping classes, 5) lack of self-

motivation, 6) health related issues, 7) lack of involvement and participation on classes (fear of embarrassment), 8) lack of basic knowledge needed as a pre-requisite for the course and, 9) inadequate use of social networks; and the second one being inherent to the teacher (26.6\%): 1) Lack of teacher's feedback on course contents and school assignments, 2) Bad student - teacher relationship, 3) Poor professors' familiarity with the course contents. 4) Poor teaching methods and technics, 5) Evaluation criteria not being observed (as stated on syllabus) 6) professor's nonattendances and, 7) Scarce simulation practices. Since these two are the main protagonists on the learning process, far beyond new technologies and innovations is of great importance the return to the essence of the academy: To educate for life and to transcend trough inherited knowledge generation after generation.

Through this exercise it is possible to identify opportunity areas, that are in need of attention to change in a favorable way the academic failure and school dropout rates, such as the actualization of course syllabus and school assignments of those courses with high rates of reprobation; also the diversification of teaching and learning strategies, the reinforcement of the student and teacher rolls in the learning process; the improvement on evaluation methods and criteria, and the construction of study habits.

Due to the later, it is important to continue with the academic journey analysis, to determine continuous improvement actions on the students' academic formation, such as the creation of regularization and/or remedial education program for first year students and the academic assessorial program consolidation.

\section{References}

Amado, M. M. G., Velázquez, Á. G., Páez, R. A. B., Luján, B. I. S., \& Bernal, C. A. S. (2014). Cause of failure in engineering from the perspective of academics and administrators. Science and Technology, 14, 233-250. 
De la Garza Aguilar, J. (2013). The evaluation of educational programs of the higher level in Mexico: Advances and perspectives. Educational Profiles, 35(SPE), 33-45.

Fernández, O. M. Á., Ortiz, M. A., Ponce, R. E. R., Fajardo, O. G., Jiménez, G. I., \& Mazón, R. J. J. (2017). Failure in Medicine students of the National Autonomous University of Mexico. Higher Medical Education, 31(4), 1-17.

Llanes Castillo, A., Cervantes López, M., Pena Maldonado, A., \& Saldivar González, A. (2013). Factors associated with the failure of the students of the Bachelor of Surgeon. Rev Esc Med Dr J Sierra, 27(1), 31-40.

Martínez, M. M. d. 1. L., Lima, J. V., Padilha, M. G. N., \& Montes, J. A. J. (1998). Multireferential analysis of the failure Phenomenon in Mexican University Students. School and Educational Psychology, 2(2), 161-174.

Martínez, D. N., Sánchez, L. E. U., Hernández, D. Z., Sánchez, H. F., \& Salazar, E. M. D. Á. (2017). Causes associated with school failure in nursing students. Tuxpan Agricultural Biological Journal, 5(2), 41-47.

Quintela, D. G. E. (2013). University dropout, a sociological approach to the decision-making process of students. Society Today(24), 83-106.

Rodriguez, A. B., Espinoza, J., Ramirez, L. J., \& Ganga, A. (2018). University dropout: New methodological analysis. University Education, 11(6), 107-118.

Salazar, C. C., \& Espinoza, C. M. R. (2017). Main causes of failure of students in the fifth semester groups six and eight of the preparatory school number three. Chapter I Background). Con-Science High School Science Bulletin, 3(4).

Saucedo, F. M., Perera, J. J. D., Maldonado, S. B., \& Padilla, H. A. S. (2014). Failure indicators: Faculty of educational sciences (UNACAR) / Failing rates: Faculty of Educational Sciences (UNACAR). RIDE Ibero-American Magazine for Educational Research and Development, 5(9), 96-106.

Torres-Zapata, Á. E., Rivera Domínguez, J., Flores López, P., García Reyes, M. D. P., \& Castillo Trejo, D. A. (2020). Failure, a symptom of school dropout in Nutrition at the Universidad Autónoma del Carmen. RIDE. Ibero-American Journal for Educational Research and Development, 10(20).

Torres, A., Acuña, J., Guadarrama, C., Solís, O., \& Flores, P. (2017). University dropout. An approach to the characteristics of school dropout in students of the Bachelor of Nutrition for decision making. Transformation (with) Educational Science. Our Voices. Our Actions, 2(4), 12-20.

Vargas, R., Brito, A., Leal, M. A., De la Cruz, C., \& Fernández, R. (2015). Determination of risk factors for University Failure in the Health area. Electronic Magazine of PortalesMedicos.com, 10(15).

Velázquez Narváez, Y., \& González Medina, M. A. (2017). Factors associated with student persistence: The case of the UAMM-UAT. High School Magazine, 46(184), 117-138.Available at: https://dx.doi.org/10.1016/j.resu.2017.11.003.

Yépez-Herrera, E. R., Rivera-Heredia, M. E., Valadez-Sierra, M., Pérez-Daniel, M. R., \& González-Betanzos, F. (2019). Towards an understanding of university failure in engineering careers in Ecuador and Mexico. Education and Development Magazine, 48, 41-52.

\footnotetext{
International Journal of Educational

Studies

Vol. 3, No.2, pp. 48-52

2020

DOI: $10.53935 / 2641-533 x . v 3 i 2.140$

"Corresponding Author: Damián-Notario Jade

Isabel

Funding: This study received no specific

financial support.

Article History:

Received: 2 March 2020

Revised: 15 May 2020

Accepted: 7 July 2020

Published: 5 August 2020

(C) 2020 by the authors; licensee Academic

Publishing Group
}

| 52 